\title{
Research Paper: The Role of Self-efficacy Beliefs in Psychological Symptoms and Clinical Outcomes of Primary Chronic Headache
}

\author{
Alia Saberi ${ }^{1}$ (D), Sajjad Rezaei ${ }^{2,3^{*}}$ iD, Fatemeh Shabani ${ }^{4}$, Samaneh Ghorbani Shirkouhi $^{3}$ \\ 1. Neuroscience Research Center, Department of Neurology, PourSina Hospital, School of Medicine, Guilan University of Medical Sciences, Rasht, Iran \\ 2. Department of Psychology, Faculty of Literature and Humanities, University of Guilan, Rasht, Iran. \\ 3. Neuroscience Research Center, Guilan University of Medical Sciences, Rasht, Iran. \\ 4. Guilan Road Trauma Research Center, School of Medicine, Guilan University of Medical Sciences, Rasht, Iran.
}

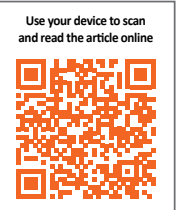

Crtation: Saberi, A., Rezaei, S., Shabani, F., \& Ghorbani Shirkouhi, S. (2019). The Role of Self-efficacy Beliefs in Psychological Symptoms and Clinical Outcomes of Primary Chronic Headache. Journal of Practice in Clinical Psychology, 7(3), $175-186$. http://dx.doi.org/10.32598/jpcp.7.3.175

http://dx.doi.org/10.32598/jpcp.7.3.175

\section{Keywords:}

Self Efficacy, Pain, Headache Disorders, Depression, Anxiety

\section{ABSTRACT}

Objective: Headache is one of the common complaints of referral patients. The prevalence of symptoms of depression and anxiety in patients with headache is significant. The previous researches suggested the role of self-efficacy of pain in modifying psychological symptoms and improving clinical outcomes. The current study aimed at investigating the role of selfefficacy beliefs of pain in psychiatric symptoms and clinical outcomes of patients with chronic headache.

Methods: The current descriptive cross-sectional study was performed on 106 patients with chronic primary headache referred to neurology clinics of Guilan University of Medical Sciences from September 2016 to March 2017. Patients responded to questions of pain selfefficacy beliefs scales, Hospital Anxiety and Depression Scale (HADS), and Visual Analogue Scale (VAS). Data were analyzed by multivariate hierarchical regression.

Results: The results of Pearson correlation coefficient showed a reverse and significant relationship between pain self-efficacy beliefs and pain severity $(\mathrm{r}=-0.25, \mathrm{P}=0.009)$. In the regression analysis, after controlling demographic variables, self-efficacy beliefs were able to predict the pain severity scale $(\mathrm{F}=4.570, \mathrm{P}=0.035)$ and anxiety $(\mathrm{F}=4.414, \mathrm{P}=0.038)$. There was also a significant non-linear quadratic correlation between the severity of pain with headache frequency $(\mathrm{F}=3.377, \mathrm{P}=0.038)$.

Conclusion: Self-efficacy beliefs are more correlated with the reduction of the severity of pain in chronic headache and can predict it. It seems that these types of beliefs can play a protective role against anxiety and headache frequency in patients with chronic headache.

\section{* Corresponding Author:}

Sajjad Rezaei, PhD.

Address: Department of Psychology, Faculty of Literature and Humanities, University of Guilan, Rasht, Iran.

Tel: +98 (13) 33690539

E-mail: rezaei_psy@hotmail.com 


\section{Highlights}

- Self-efficacy beliefs can reduce the severity of pain in chronic headache and also predict it.

- Self-efficacy beliefs can play a protective role against anxiety and headache frequency in patients with chronic headache.

\section{Plain Language Summary}

Chronic headache refers to a headache that lasts more than 15 days per month for at least 3 months. It is classified into 2 types of primary and secondary. Self-efficacy refers to an individual's belief in his or her capacity to do necessary behaviors to produce specific performance attainments. It is one of the psychological factors with modifying effects on the level of pain experienced by the individual. Previous studies indicate that pain self-efficacy can reduce pain, anxiety, depression, and other complications associated with chronic disorders. High levels of pain self-efficacy beliefs are associated with reduced severity of pain, and fewer symptoms of anxiety and even its moderate to high levels are associated with a reduction of attacks frequency. Teaching such beliefs may, therefore, affect the severity and frequency of headache.

\section{Introduction}



ain is an inseparable part of human's life that has a key protective role (Vranken, 2014). Persistent pain can change the central and peripheral nervous system through neuroplasticity phenomenon and peripheral and central sensitization (Paknejad, Asghari, Rahiminezhad, Rostami, \& Taheri, 2014). According to "International Association for the Study of Pain" definition, pain is an unpleasant sensory or emotional experience caused by actual or potential harm and has two dimensions of sensory and emotional. The sensory dimension refers to the severity of pain and its emotional dimension to the unpleasantness experienced by the individual. Pain is divided into two groups in terms of temporal profile, including acute (lasts less than three months) and chronic (persists for at least three months) (Gharaei, Azadfallah, \& Tavallaei, 2012).

In the classification of chronic pain, headache is a common complaint (Kristoffersen, Grande, Aaseth, Lundqvist, \& Russell, 2012). It is one of the most common complaints in neurology clinics (Behrouz, Amini, Abedi, \& Ghasemi, 2013; Kachoei, Amelly, Sharifibonnab, Tavallaei, \& Keshavarzi, 2009; Kurt \& Kaplan, 2008) .

According to the International Classification of Headache Disorders; 3rd edition -Beta version (ICHD- $\beta$ III), chronic headache refers to a headache that lasts more than 15 days per month and more than three months (Ashjazadeh \& Jowkar, 2015; Mirzaei, Khorvash, Ghasemi, Memar-Montazerin, \& Khazaeili, 2016; Naderinabi et al., 2017; Saberi, Roudbary, Elyasi, \& Kazemnejad Leyli, 2013). According to the International Headache Society (IHS) classification, headache includes two types of primary and secondary. The present study examined primary chronic headache (0Naderinabi et al., 2017; Saberi, Nemati, Shakib, Kazemnejad, \& Maleki, 2012).

Frequent and severe headaches can impress the quality of life (Behrouz et al., 2013; Kurt \& Kaplan, 2008). Depression and especially anxiety have a greater chance of comorbidity with migraine headache, and these two symptoms significantly contribute to the overuse of medications for relieving headache. Researchers conclude that better outcomes can be accomplished in patients with headache through screening anxiety and depression and controlling them (Lampl et al., 2016; Mirzaei et al., 2016; Zebenholzer et al., 2016). Since depression and anxiety have a dramatic effect on the quality of life of patients with headache and increase the cost of care, multidimensional approaches to treat headache is mandatory for decreasing personal, occupational, and social disabilities in patients with headache (Zebenholzer et al., 2016).

Depression and anxiety symptoms are highly prevalent among Iranian patients with headache. Chitsaz et al., concluded that the likelihood of developing headache is 2.35 times higher in people with moderate depression, 2.67 times higher in patients with moderate anxiety, and 2.7 times higher in patients with severe anxiety than the ones with none of these symptoms (Chitsaz \& Ghorbani, 2005). 
The researchers recommend that the comorbid psychological aspects of headache should also be assessed for the diagnosis, prognosis, and treatment of chronic headaches. Self-efficacy is one of the psychological factors with modifying effects on the level of pain experienced by the individual (Rezaei, Afsharnejad, Moosavi, Yousefzadeh, \& Soltani, 2012). According to Bandura's theory of social learning, self-efficacy refers to the individual's feeling of confidence in own ability to achieve a desired outcome. This construct determines the individual's amount of effort and persistence in overcoming irritating problems and experiences (Bandura, 1977). This concept is the individual's degree of confidence in own ability to maintain functioning in spite of pain (Arnstein, Caudill, Mandle, Norris, \& Beasley, 1999; Jensen, Turner, \& Romano, 1991; Marks \& Allegrante, 2005; Rezaei et al., 2012). Generally, a higher self-efficacy helps to promote and preserve the desirable effects of rehabilitation and contributes to the use of pain coping strategies, pain and disability control, adaptive psychological functioning and desirable treatment outcomes in patients with chronic pain (Rezaei et al., 2012).

In one study, Kalapurakkel et al.,(Kalapurakkel, Carpino, Lebel, \& Simons, 2014) found that pain self-efficacy and acceptance of the reality of pain are associated with reduced disability, improved academic performance, and fewer depression symptoms. In another study, Carpino et al., (Carpino, Segal, Logan, Lebel, \& Simons, 2014) found that pain self-efficacy improves functional ability and academic performance in adolescents with headache by reducing pain-related fear. They also suggested that promoting pain self-efficacy beliefs can be a key mechanism for improving behavioral outcomes.

The prevalence of headache is very high (Bahrami, Zebardast, Zibaei, Mohammadzadeh, \& Zabandan, 2012) and imposes huge burden to community health systems (Börsbo, Gerdle, \& Peolsson, 2010). On the other hand for treating the pain especially chronic pain, prescription of pain killers has many side effects mostly on gastrointestinal system. The evidence suggests that NSAIDs used as pain killer drugs increase the risk of lower GI bleeding and perforation to a similar extent observed in the upper GI tract. Newer treatment including selective cyclooxygenase- 2 inhibitors are introduced with the same beneficial effects as nonselective NSAIDs with less GI toxicity in the upper GI tract and probably in the lower GI tract. Also, overall mortality due to these complications is also decreased, but the in-hospital case fatality for upper and lower GI complication events is constant despite the new therapeutic and preventive strategies (Sostres, Gargallo, \& Lanas,
2013). Therefore, it is essential to use other treatment methods to avoid the complications of pain relief drugs and improve the quality of life of patients.

Previous studies show that pain self-efficacy can have a role in reducing pain, anxiety, depression and other complications associated with chronic disorders (Börsbo, Gerdle, \& Peolsson, 2010; French et al., 2000; Hellström, Vahlberg, Urell, \& Emtner, 2009; Rezaei et al., 2012; Tahmassian \& Moghadam, 2011; Wu et al., 2013). Also some findings suggest that clinician-conveyed expectations can enhance the benefit of treatments mediated by improved patient self-efficacy (Lo, Balasubramanyam, Barbo, Street, \& Suarez-Almazor, 2016). But these studies did not focus on headache especially chronic headache, also such studies are not yet extensively carried out in the highly-populated communities. Therefor the present study aimed at answering the question of whether there is a relationship between self-efficacy beliefs and psychological symptoms and clinical outcomes in patients with headache irrespective of demographic and background differences.

\section{Methods}

The present descriptive cross-sectional study was conducted on patients with primary chronic headache selected through consecutive sampling. It is a sampling technique in which every subject meeting the criteria of inclusion is selected until the required sample size is achieved (Polit \& Beck, 2009). The statistical population included all patients with chronic primary headache referred to neurology clinics of Guilan University of Medical Sciences from September 2016 to March 2017. The sample size was determined 98 subjects in accordance with the $\mathrm{F}$ ratio for a maximum of five variables entered into the prediction block (1 pain self-efficacy variable and 5 covariate variables, including age, gender, education, marital status and associated illness) using $\mathrm{G} \times$ Power 3.1.9.2 (Faul, Erdfelder, Buchner, \& Lang, 2009 ) and taking into account a probability of type- 1 error (alpha) of 0.05 (95\% confidence interval), accep table test power of 0.8 and medium effect size of $\mathrm{f} 2=0.15$. It was increased to 107 to manage the outliers and the unsuccessful completion of tests for $10 \%$ dropout.

Inclusion criteria: Meeting the criteria for primary chronic headache and referring to the neurology clinics of Guilan University of Medical Sciences from September 2016 to March 2017.

Exclusion criteria: Unwillingness to participate in study, poor cooperation, inability to respond to the ex- 
aminer's questions due to the severity of pain, acute headache, secondary chronic headaches as diagnosed by the IHS criteria and a neurologist.

\section{Procedure}

Following the diagnosis made by a neurologist, irrespective of their demographic and professional characteristics, the candidate patients were referred to a trained examiner in another room in the same clinic to talk about participation in the study and briefing on the confidentiality of their data and submiting their informed consent. The patients unable to talk at that time for any reason or the ones with a headache attack that distracted them from understanding the test items were asked to refer for an interview and assessment on a later time when the examiner and specialist were both present and the disturbing conditions had subsided.

For the assessment, the patients' demographic and background variables (including age, gender, education, occupation and marital status) were collected using a researcher-made checklist. The patients were also asked about the frequency of their headache attacks (per month), the mean duration of their headache from the onset of the first attack (in month) and the mean duration of each headache attack (in hour). The mean severity of the headache often experienced by each patient was then measured using the VAS. All the patients were then asked to answer the Pain Self-Efficacy Scale and the Hospital Anxiety and Depression Scale (HADS) according to the given instructions. All procedures performed in the present study involving human participants were in accordance with the ethical standards of the institutional and/or national research committee and with those of the 1964 Helsinki Declaration and its later amendments or comparable ethical standards. The current article does not contain any studies on animals, and the authors declare that they have no conflict of interest. Informed consent was obtained from all individual participants included in the study.

\section{Tools}

The Visual Analogue Scale (VAS) for the severity of pain: A horizontal 100-mm line was used for the Visual Analog Scale (VAS), anchored with 'no pain' (0) and 'worst pain' (100). It was developed by Huskisson (1974) and Participants marked their level of pain 'right now' on this line with a slash. The reliability and validity of the VAS as a measure of pain is established in multiple, diverse populations (Seymour, 1982).
The Pain Self-Efficacy Scale: The current study employed the 6-item Self-Efficacy for Managing Chronic Disease Scale developed and standardized at the Center for Epidemiological Studies of Stanford University by Lorig et al.,. Each item is scored from 0 for "Not at All Confident" to 10 for "Totally Confident" and higher scores indicate higher self-efficacy. Its internal consistency is reported 0.91 (Lorig, Chastain, Ung, Shoor, \& Holman, 1989). The Persian version of this scale was validated in a population of patients with chronic pain and its internal consistency was reported with a Cronbach's alpha of 0.87 and its test-retest reliability with a two-week interval was reported as 0.73 . Also, the two measurements did not show any significant differences.

The factor structure of the scale was assessed using the exploratory factor analysis and the results showed that the six items of the scale were loaded on one factor, namely pain self-efficacy. To assign the construct and criterion validity of the scale using hierarchical regression analysis, its scores significantly predicted the variance in the scores of the "fear of movement", "depression", "disability" and "coping strategies" tests, even when the confounding effects of age, severity, and duration of pain and duration of medication use were controlled (Rezaei et al., 2012) .

The Hospital Anxiety and Depression Scale (HADS): This 14-item self-reporting scale (with seven items on depression and seven on anxiety) is designed to screen the presence and severity of depression and anxiety symptoms. Its completion takes less than five minutes, and assesses the subjects aged 16 and above (Kaviani, Seyfourian, Sharifi, \& Ebrahimkhani, 2009; McCue, Buchanan, \& Martin, 2006). Physical symptoms are eliminated from the scale to reduce the false positive diagnosis. Each item is scored from 0 to 3 and the total score for each subscale (depression and anxiety) ranges from 0 to 21, and higher scores indicate severer symptoms. The internal consistency was confirmed with a Cronbach's alpha of 0.89 for the anxiety subscale and 0.85 for the depression subscale, and the construct validity of the scale was deemed satisfactory using relevant scales (Kaviani et al., 2009).

\section{Statistical analysis}

The collected data were encoded and then analyzed with SPSS V. 20, and the relationship between the variables was determined using the Pearson correlation coefficient and Spearman's correlation coefficient (rho). The difference between the male and female groups of patients was determined using the independent student 
t-test, and Mann-Whitney's U-test was used to compare the ordinal mean of the variables for the non-normallydistributed data (based on the Kolmogorov-Smirnov test). The hierarchical multivariate regression analysis was used to determine whether, after controlling the demographic variables, the self-efficacy belief scores could predict the patients' scores of headache, depression, and anxiety. Before performing this analysis, the assumption of the normal distribution of the criterion variable in the regression analysis and the assumption of the independence of the prediction errors and the absence of autocorrelation between the errors were verified.

\section{Results}

A total of 106 patients (22 males and 84 females) with a Mean \pm SD age of $38.46 \pm 13.33$ years participated in the current study. The data of one patient was incomplete and was removed. Table 1 presents the frequency of the demographic details of the patients with headache and the frequency distribution of the different types of head- ache. Table 2 presents the mean and standard deviation of the demographic details and Pearson's and Spearman's correlation coefficients for the study variables.

Hypothyroidism was the most common comorbid condition of chronic headache $(n=6.5 \%)$. The most common types of chronic headache in the participants included chronic tension headache $(51.9 \%)$, chronic migraine headache $(25.5 \%)$, and hemicrania continua $(7.5 \%)$, in respective order.

The results presented in Table 2 showed an inverse significant relationship between self-efficacy beliefs and the severity of pain as per the VAS $(\mathrm{r}=-0.25, \mathrm{P}=0.009)$, which means that the severity of pain reduced with increased pain self-efficacy beliefs. Nevertheless, no significant relationships were observed between self-efficacy beliefs and the other outcomes such as anxiety and depression $(\mathrm{P}>0.05)$. The analysis using Spearman's correlation coefficient (rho) showed no significant relationships be-

Table 1. The Frequency percentage of the demographic and background variables of the patients with primary chronic headache $(n=106)$

\begin{tabular}{|c|c|c|}
\hline Variable & Variable Classification & NO. (\%) \\
\hline \multirow{5}{*}{ Job status } & Office / specialist & 18(17.0) \\
\hline & Skills / professional & 26(24.5) \\
\hline & Simple or manually & $6(5.7)$ \\
\hline & Unemployed & $55(51.9)$ \\
\hline & Unspecified & $1(0.9)$ \\
\hline \multirow{3}{*}{ Marital status } & Single & $33(31.1)$ \\
\hline & Married & $72(67.9)$ \\
\hline & Unspecified & $1(0.9)$ \\
\hline \multirow{2}{*}{ Associated illness } & Yes & 21(19.8) \\
\hline & No & $85(80.2)$ \\
\hline \multirow{10}{*}{ Types of chronic headaches } & Cluster headache & $3(2.8)$ \\
\hline & Hemi-crania continua & $8(7.5)$ \\
\hline & SUNCT syndrome & $1(0.9)$ \\
\hline & Exertional & $1(0.9)$ \\
\hline & Headache after sough with long-term chronic headache & $1(0.9)$ \\
\hline & Chronic migraine headaches & $27(25.5)$ \\
\hline & Chronic tension headaches & $55(51.9)$ \\
\hline & Persistent headache half-head & $4(3.8)$ \\
\hline & New daily persistent headache & $2(1.9)$ \\
\hline & Unspecified & $4(3.8)$ \\
\hline
\end{tabular}


Table 2. The descriptive statistics and correlation coefficient matrices in variabels $(n=106)$

\begin{tabular}{|c|c|c|c|c|c|c|c|c|c|c|c|}
\hline Characteristics & Mean $\pm S D$ & Range & 1 & 2 & 3 & 4 & 5 & 6 & 7 & 8 & 9 \\
\hline 1. Pain self-efficacy & $42.99 \pm 12.47$ & $0-60$ & 1 & & & & & & & & \\
\hline 2. Anxiety & $15.84 \pm 3.25$ & $9-24$ & 0.187 & 1 & & & & & & & \\
\hline 3. Depression & $17.95 \pm 3.13$ & $10-26$ & -0.084 & 0.148 & 1 & & & & & & \\
\hline 4. Age & $38.46 \pm 13.33$ & $17-76$ & 0.068 & -0.086 & 0.081 & 1 & & & & & \\
\hline 5. VAS $^{\mathrm{b}}$ & $66.83 \pm 21.42$ & $20-100$ & $-0.252^{*}$ & -0.146 & 0.070 & 0.132 & 1 & & & & \\
\hline 6. Education (in year) & $12.70 \pm 4.84$ & $3-19$ & 0.048 & $0.215^{* *}$ & -0.086 & $-0.475^{*}$ & $-0.209 * *$ & 1 & & & \\
\hline $\begin{array}{l}\text { 7. Headache duration } \\
\text { (in month) }\end{array}$ & $80.45 \pm 86.35^{a}$ & $3-242$ & -0.012 & 0.166 & 0.036 & 0.128 & 0.206 & 0.174 & 1 & & \\
\hline $\begin{array}{l}\text { 8. Duration of head- } \\
\text { ache attack (in hour) }\end{array}$ & $10.89 \pm 13.70^{\mathrm{a}}$ & $1-72$ & -0.009 & 0.040 & -0.024 & -0.065 & $0.405^{*}$ & 0.137 & $0.244^{*}$ & 1 & \\
\hline $\begin{array}{l}\text { 9. Number of } \\
\text { headache attacks (per } \\
\text { month) }\end{array}$ & $7.25 \pm 8.27^{a}$ & $10-30$ & -0.117 & -0.131 & 0.147 & -0.052 & $0.391 *$ & -0.167 & $-0.202^{* *}$ & $0.254^{*}$ & 1 \\
\hline
\end{tabular}

${ }^{*} \mathrm{P}<0.001 ;{ }^{* *} \mathrm{P}<0.005 ;$; . Results of rho spearman correlation; ${ }^{\text {b }}$. Visual Analogue Scale

tween self-efficacy beliefs and the other demographic and psychological variables at the ordinal level $(\mathrm{P}>0.05)$.

The Kolmogorov-Smirnov test results showed that headache duration, headache frequency, and duration of headache attacks were not normally distributed; therefore, Mann-Whitney's U-test was used to determine the intergroup differences of these variables. Comparing the two groups of male and female patients and the two groups of patients with headache with and without an associated illness showed no differences in terms of the headache-related variables including the duration of headache (in month), the mean duration of each headache (in hour), the frequency and severity of headaches (based on the VAS) or the psychological variables ( $\mathrm{P}>0.05)$. In addition, comparing the two groups of single and married patients only showed that the married patients had

Table 3. The hierarchical multivariate linear regression analysis for predicting the severity in variables after controlling the demographic factors

\begin{tabular}{|c|c|c|c|c|c|c|c|c|c|c|}
\hline & \multirow{2}{*}{ Criterion } & \multirow{2}{*}{ Step and Variable } & \multirow{2}{*}{$\mathbf{R 2}$} & \multirow{2}{*}{$\begin{array}{c}\text { R2 } \\
\text { Change }\end{array}$} & \multirow{2}{*}{$\begin{array}{c}\text { F } \\
\text { Change }\end{array}$} & \multirow{2}{*}{$\begin{array}{l}\text { Beta to } \\
\text { Enter }^{\text {a }}\end{array}$} & \multicolumn{2}{|c|}{$95 \% \mathrm{Cl}^{b}$} & \multirow{2}{*}{$\mathbf{P}$} & \multirow{2}{*}{$\mathrm{DW}^{\mathrm{c}}$} \\
\hline & & & & & & & Lower & Upper & & \\
\hline \multirow{6}{*}{$\frac{n}{s}$} & \multirow{5}{*}{ Demographics } & Age & & & & -0.74 & -0.508 & 0.269 & 0.543 & \multirow{6}{*}{1.892} \\
\hline & & Gender & & & & 0.108 & -4.804 & 16.341 & 0.282 & \\
\hline & & Education level & 0.117 & 0.117 & 2.611 & -0.136 & -1.607 & 0.395 & 0.232 & \\
\hline & & Marital status & & & & 0.275 & 2.061 & 23.065 & 0.020 & \\
\hline & & Associated illness & & & & 0.092 & -5.517 & 15.400 & 0.351 & \\
\hline & Pain self-efficacy & & 0.156 & 0.039 & 4.570 & -0.206 & -0.686 & -0.025 & 0.035 & \\
\hline \multirow{6}{*}{ 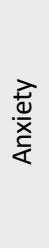 } & \multirow{5}{*}{ Demographics } & Age & & & & -0.037 & -0.070 & 0.052 & 0.768 & \multirow{6}{*}{2.042} \\
\hline & & Gender & & & & -0.080 & -2.314 & 1.006 & 0.436 & \\
\hline & & Education level & 0.060 & 0.060 & 1.253 & 0.237 & 0.003 & 0.317 & 0.046 & \\
\hline & & Marital status & & & & 0.097 & -0.974 & 2.323 & 0.419 & \\
\hline & & Associated illness & & & & -0.068 & -2.196 & 1.088 & 0.505 & \\
\hline & Pain self-efficacy & & 0.100 & 0.041 & 4.414 & -0.209 & 0.003 & 0.107 & 0.038 & \\
\hline \multirow{6}{*}{ 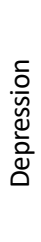 } & & Age & & & & 0.020 & -0.054 & 0.063 & 0.875 & \multirow{6}{*}{1.771} \\
\hline & & Gender & & & & 0.120 & -2.606 & 2.577 & 0.222 & \\
\hline & Demographics & Education level & 0.033 & 0.033 & 0.668 & -0.079 & -0.201 & 0.100 & 0.508 & \\
\hline & & Marital status & & & & 0.044 & -1.294 & 1.868 & 0.719 & \\
\hline & & Associated illness & & & & 0.091 & -0.874 & 2.275 & 0.379 & \\
\hline & Pain self-efficacy & & 0.036 & 0.003 & 0.354 & -0.061 & -0.066 & 0.107 & 0.553 & \\
\hline
\end{tabular}

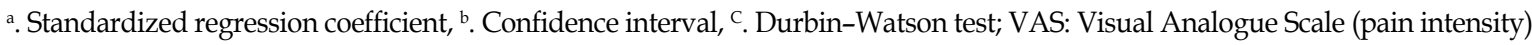


Table 4. The curve estimation regressions in variables with $95 \%$ confidence interval

\begin{tabular}{ccccccc}
\hline Criterion Variable & R2 & F & DF1 & DF2 & P & DW \\
\hline Headache duration & 0.005 & 0.244 & 2 & 103 & 0.784 & 1.991 \\
Duration of headache attack & 0.007 & 0.379 & 2 & 103 & 0.686 & 2.040 \\
Frequency of headache & 0.063 & 3.377 & 2 & 101 & 0.038 & 2.110 \\
\hline
\end{tabular}

more severe headaches compared to the single patients (58.24 vs. 41.58 , according to the ordinal mean).

Before performing the regression analysis, the assumption of normality of the criterion variable in the regression analysis of the scores of the dependent variables (including headache duration, duration of headache attacks, frequency of headache attacks and levels of anxiety and depression) was assessed based on the independent variable (ie pain self-efficacy) using a normal P-P plot.

The normal P-P plots showed that the observed cumulative probability or points representing the standardized remainders of the criterion variables, with the exception of headache duration, duration of attacks and frequency of attacks were close to the normal line (which represents normal distribution); variables including the severity of pain, anxiety, and depression had a small deviation from normal distribution. In addition, given the statistical indices in Table 3, the results of the Durbin-Watson (DW) test revealed that the assumption of the independence of the errors for the regression analysis held for every single dependent variable and was in the accep table range of 1.5-2.5. Table 3 shows the results of the hierarchical multivariate regression analysis before and after controlling the demographic variables.

Table 3 showed that after eliminating the effect of the demographic variables, pain self-efficacy was able to predict the severity of pain $(\mathrm{P}=0.035, \mathrm{~F}=4.57)$ and anxiety $(\mathrm{P}=0.038, \mathrm{~F}=4.414)$ significantly. The Beta coefficients revealed that with each unit of increase in the standard deviation of the pain self-efficacy score, the scores of severity of pain (as per the VAS) and anxiety symptoms decreased by 0.206 and 0.209 units of standard deviation. The regression analysis could not significantly predict the depression scores. Since the P-P plot showed the deviation from normality in the three variables including headache duration, duration of headache attacks, and frequency of headache attacks, the curve estimation regression was used to predict their values based on the pain self-efficacy scores (Table 4).

The results presented in Table 4 showed a significant non-linear quadratic relationship between pain self-efficacy and the frequency of headache attacks $(\mathrm{P}=0.038$, $\mathrm{F}=3.377$ ). Figure 1 presents this curved relationship; however, the quadratic relationship could not predict

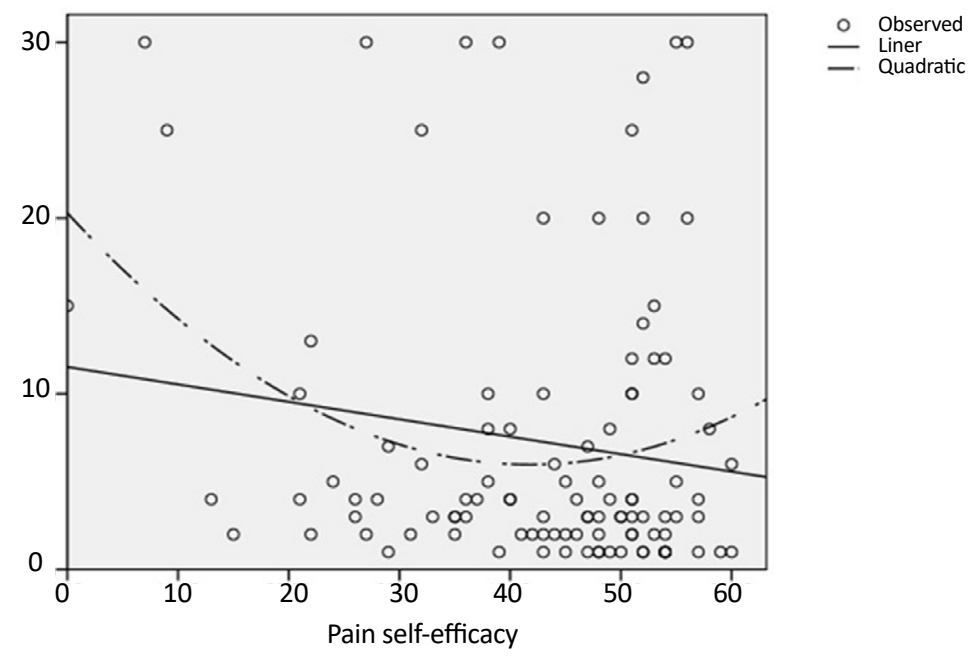

PRACTICE In CLINICAL PSYCH LOGY

Figure 1. The non-linear quadratic relationship between pain self-efficacy and the frequency of headache attacks 
headache duration and the duration of headache attacks significantly from pain self-efficacy.

Figure 1 showed a significant curved relationship between the mean frequency of headache attacks and pain self-efficacy (with its score on the $\mathrm{X}$ axis). According to this curve, the frequency of headache attacks reduced to its minimum as the scores of pain self-efficacy increased, especially in the 30 to 50 age range.

\section{Discussion}

The main finding of the correlation analysis was the inverse significant relationship between pain self-efficacy beliefs and the severity of pain. In other words, the severity of headache reduced as pain self-efficacy beliefs improved. Comparing the patients in terms of marital status showed that the married patients had more severe headaches compared to the single ones. This result is believed to be due to the older age of the married patients and also their widely different social, economic, physiological, and psychological factors; although these factors were not addressed in detail in the current study. Marital status and other demographic and background variables such as age, gender, education, and associated illnesses were controlled in the current study to answer the study questions using hierarchical regression analysis.

The hierarchical multivariate regression analysis showed that pain self-efficacy beliefs can predict the severity of pain and anxiety symptoms inversely and significantly. In line with the present findings, previous studies also showed an inverse significant relationship between self-efficacy and the severity of pain (Börsbo et al., 2010; Ferrari, Chiarotto, Pellizzer, Vanti, \& Monticone, 2016; Martin, Holroyd, \& Rokicki, 1993; Rezaei et al., 2012). This result can be explained by noting that high levels of pain self-efficacy increase social and job functioning as well as pleasurable and beneficial activities. Additionally, pain self-efficacy is a high-level cognitive process that affects the individual's coping style and problem-solving in life and helps to keep away factors such as despair that fuel pain. People with poor selfefficacy tend to avoid barriers instead of dealing with them, do not make an effort, show very little resistance and persistence and surrender to pain and report severer pain in psychological tests.

As noted, poorer pain self-efficacy predicted higher levels of anxiety in the patients. This result was in agreement with the results obtained in previous studies (Martin et al., 1993; Tahmassian \& Moghadam, 2011; Wu et al., 2013). For example, French et al., (2000) (Marks \&
Allegrante, 2005) studied 329 patients seeking treatment for headache and found an inverse relationship between anxiety and pain self-efficacy or management. To explain this finding, it can be said that people that doubt their pain management abilities have a pessimistic evaluation of themselves due to these doubts and lose their ability to control pain and experience increased levels of anxiety. The onset of headache can adversely affect academic and job performances (Behrouz et al., 2013; Kurt \& Kaplan, 2008; Zebenholzer et al., 2016); therefore, patients with poor pain self-efficacy may also experience anxiety due to their poor performances and the social consequences of failing at their job and academic duties and their accountability for them.

The present findings do not adequately support the protective role of pain self-efficacy in reducing depression in patients with headache. In disagreement with the present study, Wu et al., (2013) showed that in patients with type-II diabetes, pain self-efficacy was associated with reduced anxiety. Tahmassian et al., (2011) found that self-efficacy was an inverse determinant of depression. This disparity of findings is believed to be due to different samples and measurement tools used. In addition, the relationship between pain self-efficacy and depression in patients with headache seems to be affected by other neuropsychiatric factors not addressed in the present study.

Finally, the results of the curve estimation regression showed that pain self-efficacy did not predict headache duration or the duration of attacks, but a non-linear quadratic relationship was observed between pain selfefficacy and the frequency of headache attacks, which means that even moderate to high scores of pain self-efficacy are associated with the lowest frequency of headache attacks. A possible reason is that pain self-efficacy helps persons by employing psychological shock absorbers and increasing psychological capacities and the threshold for headache-inducing factors. Newer explanations among the Japanese patients with chronic pain (Karasawa et al., 2019) suggest that patients with high self-efficacy may have better outcomes and social survival in spite of severe and persistent pain. It is therefore understandable how better self-efficacy in the current study helps to reduce anxiety symptoms in patients with headache by maintaining and receiving social support. The assessment of the role of self-efficacy in management of pain helps the therapists and physicians to have an understanding of the ability to manage pain in their patients. Furthermore, physicians are advised to focus on self-efficacy in clinical practice, as its protective effect can reduce the symptoms of anxiety and the frequency 
of headache attacks. Future research should focus on the development of therapeutic strategies in patients with headache and using self-efficacy, since its beneficial effects in management of headache were identified in the current study as well as the other researches.

The strengths of this study include its uniform sample of patients with chronic headache; however, the results cannot be generalized to other groups of patients with chronic diseases or acute pain. The current was crosssectional and no cause and effect relationships can be inferred from its results. Some of the study variables did not have a normal distribution including headache duration, and duration and frequency of attacks, which limited the possibility of controlling the confounding variables. According to these limitations, future studies are recommended to use trial or interventional designs to test the hypothesis of whether teaching pain self-efficacy reduces the psychological symptoms and improves clinical outcomes of headache.

High levels of pain self-efficacy beliefs are associated with reduced severity of pain and fewer symptoms of anxiety and even its moderate to high levels are associated with reduction of attacks frequency. Teaching such beliefs may therefore have an effect on controlling the severity and frequency of headache.

\section{Ethical Considerations}

\section{Compliance with ethical guidelines}

All the study procedures complied with the ethical guidelines of the Declaration of Helsinki (2013).

\section{Funding}

The present paper was extracted from the MD. thesis of Fatemeh Shabani, Faculty of Medicine Guilan university of Medical Sciences.

\section{Authors' contributions}

Conceptualization: Alia Saberi, Sajjad Rezaei; Methodology: Alia Saberi; Investigation: Fatemeh Shabani; Writing-original Draft: Alia Saberi, Sajjad Rezaei, Fatemeh Shabani, Samaneh Ghorbani-Shirkouhi; Writingreview, and editing: Alia Saberi, Sajjad Rezaei, Fatemeh Shabani, Samaneh Ghorbani-Shirkouhi; Supervision: Alia Saberi.

\section{Conflict of interest}

The authors declare no conflict of interest.

\section{Acknowledgments}

Authors`special thanks go to Deputy of Research and Technology of Guilan University of Medical Sciences and the patients in PourSina Teaching Hospital for their supports.

\section{References}

Arnstein, P., Caudill, M., Mandle, C. L., Norris, A., \& Beasley, R. (1999). Self efficacy as a mediator of the relationship between pain intensity, disability and depression in chronic pain patients. Pain, 80(3), 483-491 [DOI:10.1016/S03043959(98)00220-6]

Ashjazadeh, N., \& Jowkar, H. (2015). The prevalence of migraine and tension type headaches among epileptic patients. Caspian Journal of Neurological Sciences, 1(3), 41-46. [DOI:10.18869/acadpub.cjns.1.3.41]

Bahrami, P., Zebardast, H., Zibaei, M., Mohammadzadeh, M., \& Zabandan, N. (2012). Prevalence and characteristics of headache in Khoramabad, Iran. Pain Physician, 15(4), 327-32. [PMID]

Bandura, A. (1977). Self-efficacy: Toward a unifying theory of behavioral change. Psychological Review, 84(2), 191-215. [DOI:10.1037/0033-295X.84.2.191] [PMID]

Behrouz, B., Amini, K., Abedi, A., \& Ghasemi, N. (2013). [The epidemiology and clinical characteristics of migraine and tension headaches among the patients referred to Farabi Hospital in Kermanshah city in year 2011 (Persian)]. Iranian Journal of Epidemiology, 9(1), 58-65.

Börsbo, B., Gerdle, B., \& Peolsson, M. (2010). Impact of the interaction between self-efficacy, symptoms and catastrophising on disability, quality of life and health in with chronic pain patients. Disability and Rehabilitation, 32(17), 1387-96. [DOI:10.3109/09638280903419269] [PMID]

Carpino, E., Segal, S., Logan, D., Lebel, A., \& Simons, L. E (2014). The interplay of pain-related self-efficacy and fear on functional outcomes among youth with headache. The Journal of Pain, 15(5), 527-34. [DOI:10.1016/j.jpain.2014.01.493] [PMID] [PMCID]

Chitsaz, A., \& Ghorbani, A. (2005). [Study of relative distribution of depression and anxiety in suffering from migraine and tension type headache and comparison with those who are not suffering from headache (Persian)]. Journal of Fundamentals of Mental Health, 7(25-26), 41-6.

Faul, F., Erdfelder, E., Buchner, A., \& Lang, A.G. (2009). Statistical power analyses using $G^{*}$ Power 3.1: Tests for correlation and regression analyses. Behavior Research Methods, 41(4), 1149-60. [DOI:10.3758/BRM.41.4.1149] [PMID]

Ferrari, S., Chiarotto, A., Pellizzer, M., Vanti, C., \& Monticone, M. (2016). Pain self-efficacy and fear of movement are similarly associated with pain intensity and disability in italian patients with chronic low back pain. Pain Practice, 16(8), 1040-7. [DOI:10.1111/papr.12397] [PMID] 
French, D. J., Holroyd, K. A., Pinell, C., Malinoski, P. T., O'donnell, F., \& Hill, K. R. (2000). Perceived self-efficacy and headache-related disability. Headache, 40(8), 647-56. [DOI:10.1046/j.1526-4610.2000.040008647.x] [PMID]

Gharaei Ardakani, Sh., AzadFallah, P., Tavallaei A. (2012). The effectiveness of acceptance and commitment therapy on pain experience in women with chronic pain. Journal of Clinical Psychology, 4(2), 39-50.

Hellström, K., Vahlberg, B., Urell, C., \& Emtner, M. (2009). Fear of falling, fall-related self-efficacy, anxiety and depression in individuals with chronic obstructive pulmonary disease. Clinical Rehabilitation, 23(12), 1136-44. [DOI:10.1177/0269215509342329] [PMID]

Huskisson, E. C. (1974). Measurement of pain. The Lancet, 304(7889), 1127-31. [DOI:10.1016/S0140-6736(74)90884-8]

Jensen, M. P., Turner, J. A., \& Romano, J. M. (1991). Self-efficacy and outcome expectancies: Relationship to chronic pain coping strategies and adjustment. Pain, 44(3), 263-9. [DOI:10.1016/0304-3959(91)90095-F]

Kachoei, H., Amelly, G., Sharifibonnab, M., Tavallaei, S., \& Keshavarzi, N. (2009). [Contributing factors in migraine attacks (Persian)]. Kowsar Medical Journal, 11(3), 279-84.

Kalapurakkel, S., Carpino, E., Lebel, A., \& Simons, L. (2014). "Pain can't stop me": Examining pain self-efficacy and acceptance as resilience processes among youth with chronic headache. Journal of Pediatric Psychology, 40(9), 926-33. [DOI:10.1093/jpepsy/jsu091] [PMID] [PMCID]

Karasawa, Y., Yamada, K., Iseki, M., Yamaguchi, M., Murakami, Y., Tamagawa, T., et al., (2019). Association between change in self-efficacy and reduction in disability among patients with chronic pain. PLOS One, 14(4), e0215404 [DOI:10.1371/journal.pone.0215404] [PMID] [PMCID]

Kaviani, H., Seyfourian, H., Sharifi, V., \& Ebrahimkhani, N (2009). [Reliability and validity of Anxiety and Depression Hospital Scales (HADS): Iranian patients with anxiety and depression disorders (Persian)]. Tehran University Medical Journal, 67(5), 379-85.

Kristoffersen, E. S., Grande, R. B., Aaseth, K., Lundqvist, C., \& Russell, M. B. (2012). Management of primary chronic headache in the general population: The Akershus study of chronic headache. The Journal of Headache and Pain, 13(2), 113-20. [DOI:10.1007/s10194-011-0391-8] [PMID] [PMCID]

Kurt, S., \& Kaplan, Y. (2008). Epidemiological and clinical characteristics of headache in university students. Clinical Neurology and Neurosurgery, 110(1), 46-50. [DOI:10.1016/j. clineuro.2007.09.001] [PMID]

Lampl, C., Thomas, H., Tassorelli, C., Katsarava, Z., Laínez, J. M., Lantéri-Minet, M., et al., (2016). Headache, depression and anxiety: Associations in the Eurolight project. The Journal of Headache and Pain, 17, 59. [DOI:10.1186/s10194-0160649-2] [PMID] [PMCID]

Lo, G. H. W., Balasubramanyam, A. S., Barbo, A., Street Jr, R. L., \& Suarez-Almazor, M. E. (2016). Mediated by selfefficacy status, positive clinician conveyed expectations of treatment effect reduces pain in knee osteoarthritis. Arthritis care \& research, 68(7), 952-7. [DOI:10.1002/acr.22775] [PMID] [PMCID]
Lorig, K., Chastain, R. L., Ung, E., Shoor, S., \& Holman, H. R. (1989). Development and evaluation of a scale to measure perceived self-efficacy in people with arthritis. Arthritis $\mathcal{E}$ Rheumatism, 32(1), 37-44. [DOI:10.1002/anr.1780320107]

Marks, R., \& Allegrante, J. P. (2005). A review and synthesis of research evidence for self-efficacy-enhancing interventions for reducing chronic disability: Implications for health education practice (part II). Health Promotion Practice, 6(2), 148156. [DOI:10.1177/1524839904266792] [PMID]

Martin, N. J., Holroyd, K. A., \& Rokicki, L. A. (1993). The headache self-efficacy scale: Adaptation to recurrent headaches. Headache, 33(5), 244-8.[DOI:10.1111/j.1526-4610.1993. hed3305244.x] [PMID]

McCue, P., Buchanan, T., \& Martin, C. R. (2006). Screening for psychological distress using internet administration of the Hospital Anxiety and Depression Scale (HADS) in individuals with chronic fatigue syndrome. British Journal of Clinical Psychology, 45(4), 483-98. [DOI:10.1348/014466505X82379] [PMID]

Mirzaei, S., Khorvash, F., Ghasemi, M., Memar-Montazerin S., \& Khazaeili, M. (2016). Migraine and irritable bowel syndrome: An epidemiological study. Caspian Journal of Neurological Sciensece, 4(2), 36-41. [DOI:10.18869/acadpub. cjns.2.4.36

Naderinabi, B., Saberi, A., Hashemi, M., Haghighi, M., Biazar, G., Gharehdaghi, F. A., et al., (2017). Acupuncture and botulinum toxin a injection in the treatment of chronic migraine: A randomized controlled study. Caspian Journal of Internal Medicine, 8(3), 196-204. [DOI: 10.22088/cjim.8.3.196]

Paknejad, M., Asghari, A., Rahiminezhad, A., Rostami, R., \& Taheri, A. (2014). [Factorial structure and psychometric properties of the Pain Anxiety Symptoms Scale (PASS-20) (Persian)]. Applied Psychological Research Quarterly, 5(3), 170-93.

Polit, D.F., \& Beck, C.T. (2009). Essentials of nursing research: Appraising evidence for nursing practice (essentials of nursing research). Philadelphia: Lippincott Williams \& Wilkins.

Rezaei, S., Afsharnejad, T., Moosavi, S. V., Yousefzadeh, S., \& Soltani, R. (2012). [Validation of the Persian version of pain self-efficacy scale: A psychometric chronic low back pain patients (Persian)]. The Quarterly Journal of Fundamentals of Mental Health, 13(4), 528-45.

Saberi, A., Nemati, S., Shakib, R. J., Kazemnejad, E., \& Maleki, M. (2012). Association between allergic rhinitis and migraine. Journal of Research in Medical Sciences, 17(6), 508-12. [PMID] [PMCID]

Saberi, A., Roudbary, S. A., Elyasi, N., \& Kazemnejad Leyli, E. (2013). [Comparison the serum level of prolactin among patients with chronic and episodic migraine (Persian)]. Journal of Guilan University of Medical Sciences, 22(87), 84-9.

Seymour, R. A. (1982). The use of pain scales in assessing the efficacy of analgesics in post-operative dental pain. European Journal of Clinical Pharmacology, 23(5), 441-4.[DOI:10.1007/ BF00605995] [PMID]

Sostres, C., Gargallo, C. J., \& Lanas, A. (2013). Nonsteroidal anti-inflammatory drugs and upper and lower gastrointestinal mucosal damage. Arthritis Research \& Therapy, 15(Suppl. 3), S3. [DOI:10.1186/ar4175] [PMID] [PMCID] 
Tahmassian, K., \& Moghadam, N. J. (2011). Relationship between self-efficacy and symptoms of anxiety, depression, worry and social avoidance in a normal sample of students. Iranian Journal of Psychiatry and Behavioral Sciences, 5(2), 91. [PMID] [PMCID]

Vranken, J. H. (2014). Pain in urology: The good, the bad, and the ugly. In D. M. Gainsburg, E. O., Bryson, E. A. M. Frost (Eds.), Anesthesia for Urologic Surgery (pp. 291-327). Berlin: Springer. [DOI:10.1007/978-1-4614-7363-3_14]

Wu, S. F. V., Huang, Y. C., Lee, M. C., Wang, T. J., Tung, H. H., $\& \mathrm{Wu}, \mathrm{M}$. P. (2013). Self-efficacy, self-care behavior, anxiety, and depression in T aiwanese with type 2 diabetes: A cross-sectional survey. Nursing \& Health Sciences, 15(2), 2139. [DOI:10.1111/nhs.12022] [PMID]

Zebenholzer, K., Lechner, A., Broessner, G., Lampl, C., Luthringshausen, G., Wuschitz, A., et al., (2016). Impact of depression and anxiety on burden and management of episodic and chronic headaches- A cross-sectional multicentre study in eight Austrian headache centres. The Journal of Headache and Pain, 17, 15. [DOI:10.1186/s10194-016-0603-3] [PMID] [PMCID] 
This Page Intentionally Left Blank 